0.05 level of confidence with df 38 . The results of the study showed that there was a significant difference between traditional lecture method of teaching group and multimedia based modular method of teaching group in teaching cricket rules in favour of experimental group.

\title{
164 IMPACT OF MULTIMEDIA ON TEACHING BASIC CRICKET RULES
}

Ramu Pilli Bhavan's Sri Aurobindo Junior College, Bharatiya Vidya Bhavan, Secunderabad, Andhra Pradesh, India

10.1136/bjsm.2010.078725.164

Today's classroom practices are quite different from those of yesterday. Similarly, the classroom practices in the coming century may be quite different from those of today. The shape of future school, colleges and universities is bound to change radically due to technological impact in the years to come. Multimedia means making appeal to different senses instead of one as in the traditional method. Multimedia includes high technology instructional media. The present study was to investigate the role of multimedia on teaching basic cricket rules of ML Jai Simha and Bhavan's Cricket Academy specialisation students. Forty students studying bachelor's degree in the various colleges in Hyderabad, Andhra Pradesh, India. Represented under-19years for Hyderabad Cricket Association, with the age from 18 to 20 years (mean age $=19 \pm 0.5$ years) were selected for this study. They were divided into two groups of 20 subjects each namely the traditional practical method of teaching group and multimedia based modular of teaching group (teaching cricket rules). A computer expert was consulted to develop the courseware programme to teach the basic cricket rules and it was discussed with him how to develop software based on the modules. The achievement test consisted of 100 questions. Out of 100 questions, 60 objective type questions and 40 fill in the blanks type questions were present. The total score of the test was 100. For each correct answer, the score was one and for each wrong answer the score was zero. The statistical tool used for this study was ' $t$ '-ratio. The results of the study shows that the mean values of traditional lecture method of teaching group and multimedia based modular method of teaching group were $50.75 \pm 2.89$ and $70.25 \pm 2.998$, respectively. The obtained ' $t$ '-ratio value 20.61 greater than the require table value 2.0246 for significance at 